\title{
Clinical approach to erectile dysfunction in spinal cord injured men. A review of clinical and experimental data
}

\author{
FJ Courtois $^{1,3}$, KF Charvier ${ }^{2}$, A Leriche ${ }^{2}$, DP Raymond ${ }^{3}$ and M Eyssette ${ }^{2}$ \\ ${ }^{1}$ Université du Québec à Montréal, Département de Sexologie, C.P. 8888, Succ Centre Ville, Montréal, Québec, \\ H3C 3P8, Canada; ${ }^{2}$ Hospices Civils de Lyon, Hôpital Henry Gabrielle, Route de Vourles, 69230 Saint-Genis- \\ Laval, France; ${ }^{3}$ Institut de Réadaptation de Montréal, 6300 Darlington, Montréal, Québec, H3S 2J4, Canada
}

\begin{abstract}
Despite the many developments in the area of sexual dysfunction, rehabilitation settings seldom investigate the remaining sexual function following spinal cord injury, or offer differential diagnoses of sexual dysfunction in spinal cord injured men. This article attempts to show how sexual rehabilitation should begin with a thorough assessment of the sexual function of paraplegic and tetraplegic men. Assessment includes a basic neurological examination of the perineal area and an extended clinical interview on sexual function and visceral function. The interpretation of patient evaluation is discussed in terms of a classification system adapted to sexual purposes and in terms of the differential diagnoses between sexual dysfunctions of organic, and those of predominantly psychogenic origin in the spinal cord injured patient. The organic or psychogenic contribution is discussed in terms of sophisticated procedures, where assessment of nocturnal penile tumescence (NPT) is critically evaluated and where alternatives such as urodynamic findings and skin potentials are discussed. Treatment strategies, such as intracavernous injections and cognitive-behavioural strategies adapted to different lesion types, are discussed.
\end{abstract}

Keywords: erection; sexuality; spinal cord injuries; paraplegia

\section{Introduction}

Centres that specialise in the area of sexual dysfunction have, nowadays, a variety of resources available to them, ranging from medical interventions - such as intracavernous injections, ${ }^{1-3}$ vacuum devices ${ }^{4-6}$ and surgery ${ }^{7,8}$ to psychotherapeutic ones, such as couple, group and individual therapy ${ }^{9-11}$ based on cognitivebehavioral, ${ }^{9-11}$ systemic-interactional, ${ }^{12}$ existentialhumanistic $^{12}$ and psychodynamic ${ }^{12}$ approaches. All of these approaches remain based on the initial evaluation of the patient to identify the organic and psychogenic origin of the dysfunction and to adapt treatment to the individual patient.

The study of sexual dysfunctions has, in this sense, led to the development of assessment instruments aimed at improving the diagnosis of organic and psychogenic sexual dysfunctions. Instruments have evolved from the mercury plethysmograph, ${ }^{13,14}$ to the penile cuff ${ }^{15}$ and the Rigiscan device (Dacomed, Minneapolis) $)^{16,17}$ for the measurement of penile tumescence, and from the buckling force ${ }^{18,19}$ to the stamp ring,,$^{20-22}$ snap gauge ${ }^{18,23}$ and again penile $e^{15,24}$ and Rigiscan ${ }^{16,17}$ devices for the measure of penile rigidity. Further studies have explored the advantages and limitations of daytime laboratory recordings as opposed to measurement of nocturnal penile tumescence.

Strangely enough, these developments appear to have escaped the rehabilitation environment. Despite a few attempts to consider multidisciplinary approaches to sexual dysfunction in spinal cord injured patients, ${ }^{25,26}$ rehabilitation centres have tended to focus on intracavernous injections as a sole mean of intervention and often fail to consider the differential diagnoses between organic and psychogenic dysfunction in this patient population.

In this context, our France-Quebec collaboration has aimed at developing measures to assess the residual sexual capacity of paraplegic and tetraplegic individuals to adapt to clinical interventions. The following article summarises these clinical and experimental data and gives an overview of the sexological evaluation which we now offer to spinal cord injured patients in our respective rehabilitation centers.

\section{Sexual evaluation and residual sexual capacity}

The concept of functional rehabilitation in spinal cord injury units is based on the evaluation of patients to establish remaining function and to provide rehabilitation programmes maximising this initial post-traumatic potential. In this context, physiotherapy seldom brings back walking to the tetraplegic patient, but it provides an initial evaluation of muscular strength and equilibrium to maximise the functional ability during rehabilitation. This approach is that which we encourage in the sexual rehabilitation of spinal cord injured patients: it takes into account the residual sexual capacity of the 
individual and attempts to maximise this post-traumatic potential during sexual rehabilitation. Sexual rehabilitation further benefits from the commonly used pharmacological treatments which allow the patient, if need be, to meet his pre-traumatic standards. The effectiveness of such pharmacological treatments can be enhanced by the residual erectile capacity of the individual so that evaluation becomes a necessity from our perspective.

The residual erectile capacity of spinal cord injured patients is a function of the remaining neural connections within the genital system. As illustrated in Figure 1 , the anatomical connections within the genital system include two nervous pathways, one originating from the sacral segments S2, S3, S4 of the spinal cord and involving the pudendal and pelvic nerves, the other originating from the thoracic-lumbar segments $\mathrm{T} 11$, T12, L1, L2 and involving the hypogastric, sympathic and pelvic nerves. ${ }^{27}$

Experimentally, the first of these two pathways, namely the sacral pathway, has been studied extensively at the anatomical ${ }^{28,29}$ and physiological ${ }^{30-35}$ level, as well as at the animal ${ }^{28-35}$ and human ${ }^{36-38}$ level. The thoracic-lumbar (TL) pathway, in contrast, has not been documented as thoroughly, although evidence for

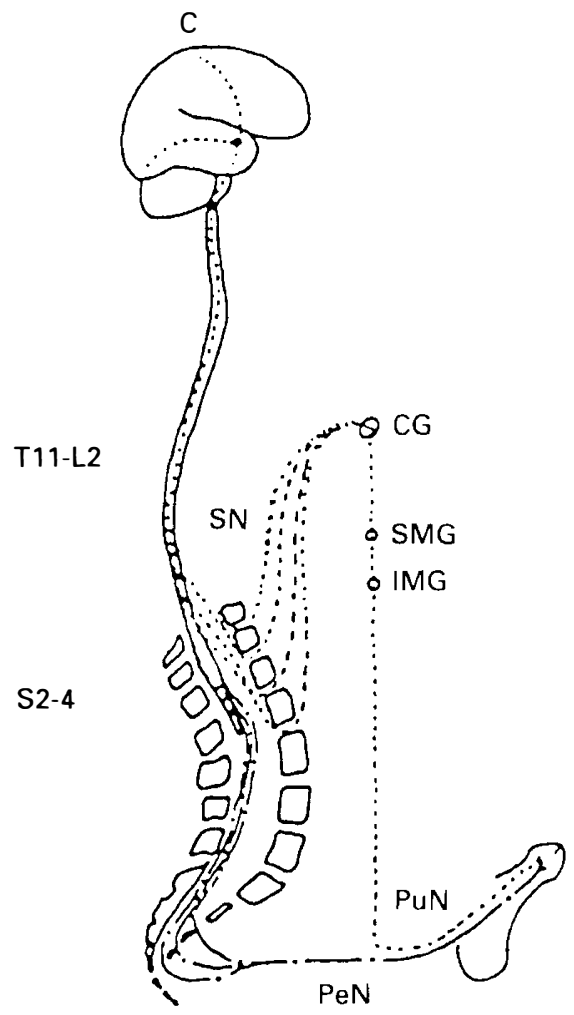

Figure 1 The innervation of the male reproductive system includes a sacral pathway (S2-4) responsible for the transmission of reflexogenic erection, and a thoracic-lumbar pathway (T11-L2) responsible for the transmission of psychogenic erection. C: cortex; CG: coeliac ganglion; IMG: inferior mesenteric ganglion; PeN: pelvic nerve; PuN: pudendal nerve; SMG: superior mesenteric ganglion; SN: splanchnic nerve its importance in the erectile process has been highlighted in the past few years. ${ }^{27,39}$

At the spinal cord injury level it has been demonstrated that the TL pathway could convey penile responses from stimulation of higher CNS structures in the absence of reflex activity from the sacral pathway. At the animal level, ${ }^{40}$ we have shown that cauda equina lesions of S1 completely interrupted reflex activity from the sacral pathway, including bladder function and penile responses to genital stimulation. Nevertheless, $85 \%$ of the animals maintained penile responses to stimulation of a hypothalamic area, a support for the hypothesis of a role for the TL pathway in mediating erection. At the human level, ${ }^{41}$ we have shown that $80 \%$ of the subjects whose lesions interrupted the sacral pathway maintained erectile responses to psychogenic stimulation. These findings, along with the previous ones, further emphasise the complementary role of the TL pathway in paraplegic subjects who have lost function from the sacral pathway. Since our data also confirm those of previous findings on the sexual function of higher lesion subjects, ${ }^{36-38}$ the overall results show that very few spinal cord injured subjects suffer from complete impotence. The vast majority maintain a residual erectile capacity upon which a sexual rehabilitation programme could be built.

\section{Sexological examination}

Evaluating remaining sexual capacity in spinal cord injured subjects requires investigation of the functional state of the pelvic region through a basic neurological examination and/or an extended clinical interview. The basic neurological examination is summarised in Table 1 and includes exploration of perineal reflexes and pelvic sensation. Four perineal reflexes are investigated: the anal reflex, the cutaneous-anal, the bulbocavernosus and the bulbo-anal reflex.

The anal reflex is elicited during a rectal touch which

Table 1 Perineal reflexes

Bulbocavernosus reflex $(S 2, S 3)$

Pressure applied onto the gland penis triggers a reflex contraction of the bulbocavernosus muscle located between the scrotum and anal sphincter. The contraction can be noted visually, upon palpation or through electromyographic (EMG) recordings

Bulbo-anal reflex $(S 3, S 4)$

Pressure applied onto the glans penis triggers a reflex contraction of the anal sphincter which can be noted during a rectal touch as well as visually or through EMG recordings

External anal sphincter (S3, S4)

Stimulation from a rectal touch triggers reflex contraction of the anal sphincter

Cutaneous-anal reflex $(S 4, S 5)$

Algic stimulation (with a needle) of the anus triggers a reflex contraction of the anal sphincter and can be noted visually as well as through EMG recordings 
normally triggers a reflex contraction of the anal sphincter. The presence of this reflex indicates positive reflex activity from the spinal segments S3, S4, whilst its absence reflects impairement of sacral activity. The cutaneous-anal reflex is elicited in response to nociceptive stimulation of the anal area which leads to a contraction of the external anal sphincter. Presence of this reflex indicates positive activity from the S4, S5 spinal segments. The bulbocavernosus and bulbo-anal reflexes are elicited in response to pressure stimulation of the glans penis which leads to contractions of the bulbocavernosus muscle and external anal sphincter respectively. These contractions can be noted visually, by palpation or during electromyographic recordings, and are indications of positive reflex activity from the $\mathrm{S} 2, \mathrm{~S} 3$ and S3, S4 spinal segments respectively.

The presence of these reflexes reflects functional activity from the sacral pathway and should be associated with retention of reflex erections. Conversely, absence of these reflexes reflects damage to the sacral pathway and absence of reflex erections but not necessarily absence of psychogenic erections. ${ }^{41}$

The evaluation of perineal reflexes is complemented by investigation of dermal sensation to specify the level of the lesion. Dermal sensation in the perineum and lower limbs is illustrated in Figure 2. It is limited to the innervation of the genital area, that is from T10 to S5, for reasons which will be understood in the discussion of the classification system below. Dermal evaluation includes tactile sensation, which travels through the posterior column system, and nociception which travels through the spino-thalamic tracts.

This basic neurological examination has allowed us to classify patients according to four categories: lesions located above the two pathways of erection (AP), lesions located between the two pathways (BTW), lesions damaging the sacral pathway but limited to the conus terminalis (CT) and lesions damaging the sacral pathway and extended to the cauda equina (CE). Each category is associated with a particular mode of sexual function. ${ }^{41,42}$ Figure 3 illustrates these modes.

Lesions above the two pathways innervating the genitals $(A P)$

These lesions are associated with reflex erections. Sexual responses appear following direct stimulation of the genitals, such as masturbation or fondling. These lesions are associated with positive perineal reflexes and with dermal sensations maintained anywhere from $\mathrm{C} 1$ to $\mathrm{T} 10$, but lost (or impaired) under T10. ${ }^{12,13}$

\section{Lesions between the dual innervation of the genital system (BTW)}

These lesions are associated with psychogenic and reflexogenic erections. As they spare sacral reflex activity, they spare erectile responses to genital stimulation; and as they spare the connections between higher centers and the TL pathway, they spare erectile
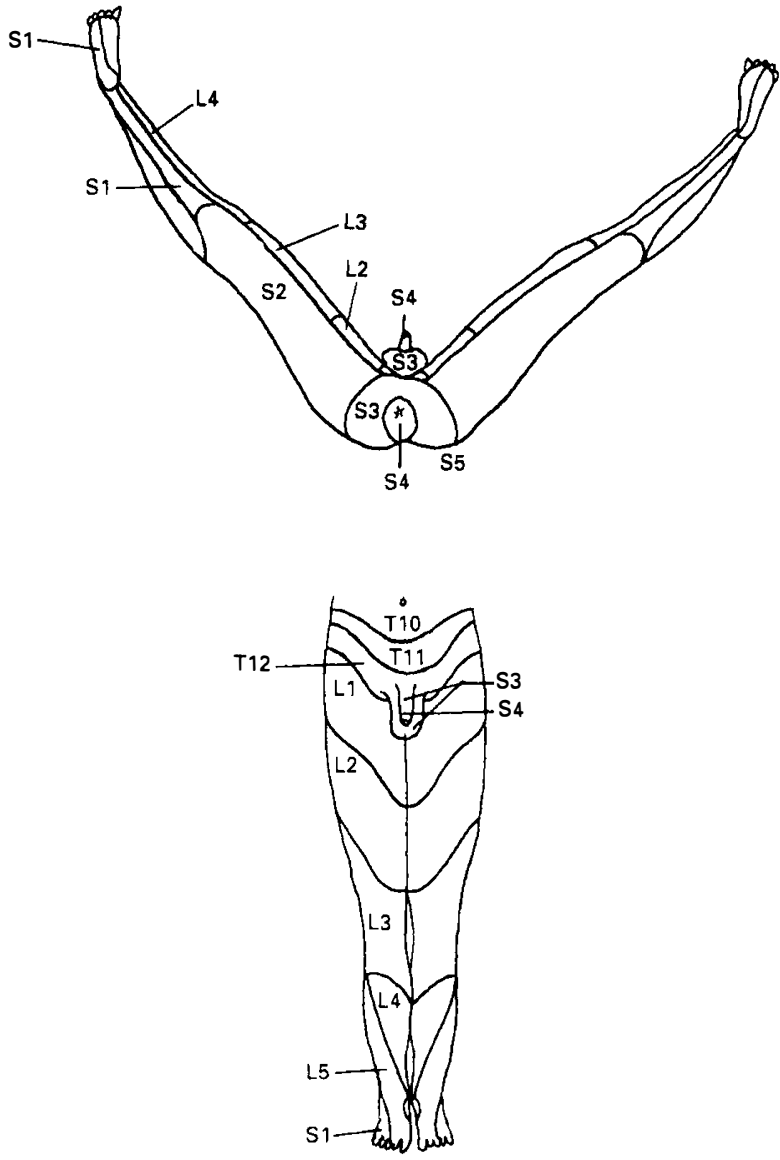

Figure 2 The evaluation of dermal sensation in the perineum and lower limbs should include investigation of tactile sensation (which is transmitted through the dorsal column system) and of nociceptive (or thermal) sensation (which is transmitted through the spino-thalamic tract). Adapted from Ditunno et al ${ }^{60}$

responses to psychogenic stimulation. These subjects have positive perineal reflexes and dermal sensation as low as $\mathrm{L}^{12,13}$ but have a loss (or impairment) of sensation from the sacral segments.

\section{Lesions damaging the sacral pathway but limited to} the conus terminalis (CT)

These lesions interrupt reflex responses from the sacral segments but spare the connections between higher centres and the TL pathway. ${ }^{41,42}$ They therefore spare erectile activity following psychogenic stimulation as it occurs in response to fantasies or to various types of non-genital stimulation including visual stimulation (watching a movie or a desirable partner), auditory stimulation (hearing a voice or a sound), olfactory stimulation (smelling a perfume or body odours) or tactile stimulation of non-genital areas (caressing the neck, ears or other body areas). Clinical evaluation generally reveals loss of perineal reflexes with anaesthesia (or paraesthesia) limited to the S1-5 region. 

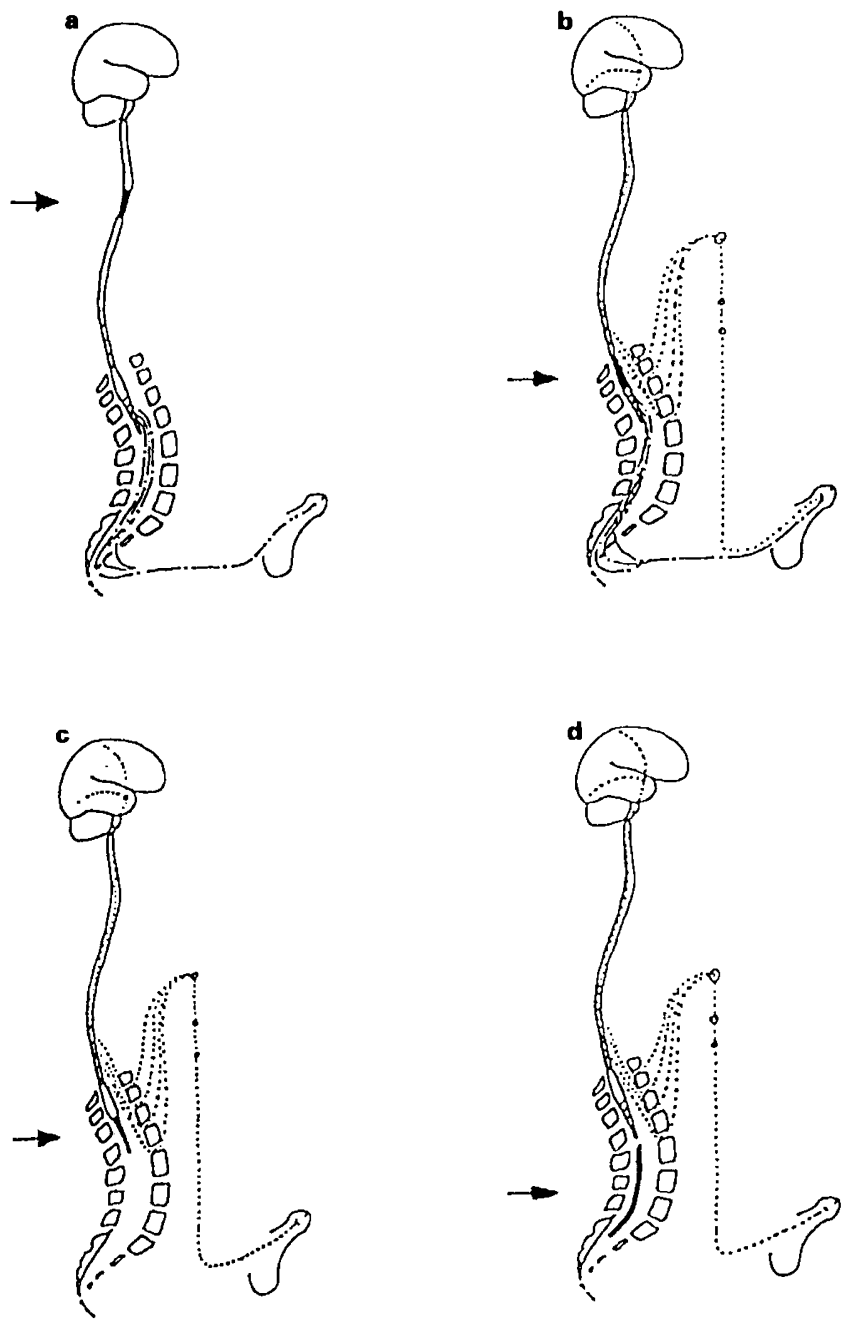

Figure 3 The lesions classification system includes (a) lesions located above the two pathways innervating the genitals (AP); (b) lesions located between the two pathways (BTW); (c) lesions damaging the sacral pathway but restricted to the conus terminalis $(\mathrm{CT})$; (d) lesions damaging the sacral pathway and extending to the cauda equina (CE)

\section{Lesions damaging the sacral pathway and extended to} the cauda equina ( $C E)$

These lesions can be of several kinds and would indeed benefit from a similar subdivision to that used in central lesions. Lesions are lower motor neuron and can occur as high as T12-L1 or as low as S4-5. Subjects can therefore lose all sexual capacity or maintain most sexual potential. For example, a cauda equina lesion to T12-L1 can abolish reflexogenic and psychogenic activity since it abolishes reflexes below the lesion level and since it interrupts the connections between higher centres and the TL pathway. In contrast, a cauda equina lesion to the lower sacral segments may limit the dysfunction to minimal reflexogenic impairment if the lesion is partial and located within the last sacral segments. Clinical examination of these lesions generally reveals a loss of perineal reflexes and anaesthesia (or paraesthesia) restricted to the genital area or extended to the hamstring or posterior thighs.
The overall neurological evaluation presented here indicates to which group the patient belongs. Once this classification is achieved, the clinician can explore differential diagnoses between organic and psychogenic dysfunctions in spinal cord injured men by comparing the prognosis of residual sexual function and the actual experience of the patient. For example, the absence of reflexogenic erections in a patient who otherwise maintains all perineal reflexes, suggests psychogenic dysfunction. Similarly, the absence of psychogenic erections in a patient whose clinical evaluation reveals a functional thoracic-lumbar pathway, suggests psychogenic aetiology. The absence of both psychogenic and reflexogenic erections in a patient whose clinical evaluation reveals extended damage to both pathways is consistent with an organic aetiology.

While the above discussion refers to clinical hypotheses, our research groups have pursued the investigation of assessment instruments, such as nocturnal penile tumescence (NPT), urodynamics and skin potentials, to explore these hypotheses.

\section{NPT versus urodynamics and skin potentials. NPT recordings}

The clinical evaluation of spinal cord injured men can be complemented with sophisticated exploration of the perineal area. Such exploration provides objective data to differentiate organic erectile dysfunctions from psychogenic ones. In this area, the studies on sleep patterns ${ }^{19,43}$ have opened the door to evaluation and experimentation in sexual function. As such, studies on sleep have shown that the phase of rapid eye movements (REM) is almost always accompanied by erections nocturnal penile tumescence (NPT). NPT can therefore be used as a diagnostic instrument whereby nocturnal erections are a sign of a psychogenic aetiology while its absence confirms the diagnosis of an organic aetiology. ${ }^{19,44-46}$

The diagnostic criteria used in NPT assessment are necessarily applied to the spinal cord injured population. However, studies on sleep patterns revealed that the erections that accompany REM sleep are not related to the content of dreams. ${ }^{43}$ The absence of 'universal' links between erotic dreams and the appearance of nocturnal erections has led us to formulate the hypothesis that nocturnal erections are primary reflexogenic responses transmitted via the sacral pathway. Paraplegic subjects, with an impaired sacral pathway, would therefore be diagnosed as organic impotent from NPT recordings, when our results show that most of these subjects maintain psychogenic erections. ${ }^{41}$

The results of our study on NPT recordings confirmed the above mentioned hypothesis and showed that positive NPT recordings primarily appear in those spinal cord injured subjects who maintain reflexogenic activity; subjects with an impaired reflex function generally lose nocturnal erections ${ }^{47}$ even if they otherwise maintain psychogenic erectile potential. ${ }^{41}$ NPT recordings should therefore be used with caution in the spinal cord injured population: while they can be a 
good diagnostic instrument for patients with higher lesions, they may be responsible for false diagnoses in lower paraplegic patients. Daytime recordings, using reflexogenic (masturbation) and psychogenic stimulation (erotic movie) ${ }^{41}$ may be preferred to NPT recordings in rehabilitation settings.

\section{Urodynamics}

The search for new instruments in the diagnosis of erectile dysfunctions in spinal cord injured subjects has led us to consider urodynamic recordings. The assumption underlying this is that bladder function is dependent upon the same sacral and thoracic-lumbar innervation as sexual function. In particular, the detrusor muscle of the bladder which is involved in micturition is innervated by parasympathetic nerve fibres originating from the $\mathrm{S} 2-4$ segments of the spinal cord; the urethral sphincter involved in continence is innervated by somatic nerve fibres originating from the S2-4 segments; and the neck of the bladder involved in continence is innervated by sympathetic fibres originating from the T10-L2 spinal segments. ${ }^{48}$ Information from bladder function may therefore give us indications on the functional state of the dual innervation of the genital system.

In a recent study, ${ }^{49}$ we explored three variables reflecting parasympathetic, somatic and sympathetic activity. The presence of bladder contractions during urodynamic recordings was interpreted as a sign of parasympathetic activity, the presence of a hypertonic urethral sphincter as a sign of sacral somatic innervation, and the presence of a hypertonic neck of bladder as a sign of sympathetic activity. The results from our preliminary study ${ }^{49}$ indicate that indeed higher lesions (AP) are associated with significantly more bladder contractions and significantly more hypertonic sphincter activity than other groups. Whilst these urodynamic findings reveal functional parasympathetic and sacral somatic innervation, these subjects usually have reflexogenic erectile function. ${ }^{41}$ Conversely, lower lesions (CT) are associated with significantly more hypertonia from the neck of the bladder than the other groups. This sign of sympathetic activity (or hyperactivity) is associated with psychogenic erectile function. ${ }^{41}$ Finally, lower lesions which are associated with absence of bladder contractions and hypotonia from the urethral sphincter and bladder neck offer signs of denervated parasympathetic, sacral somatic and sympathetic systems and should therefore be associated with a loss of both reflexogenic and psychogenic erection capacity.

Urodynamics, which is a common procedure in rehabilitation practice, can therefore offer an alternative to NPT to establish differential diagnoses of impotence in spinal cord injured men. As such, absence of reflexogenic erections in subjects showing a functional sacral pathway from urodynamics, or absence of psychogenic erections in subjects showing a functional TL pathway in urodynamics, may suggest a psycho- genic contribution to the dysfunction. Conversely, absence of both reflexogenic and psychogenic erections in individuals whose urodynamics show dysfunctional sacral and TL pathways can confirm a diagnosis of organic impotence.

\section{Skin potentials}

The search for diagnositic instruments adaptable to spinal cord injured patients, has led us to consider further the use of skin potentials. These involve stimulation of the median nerve and recordings from the penis as a sign of sympathetic activity. The rationale behind the procedure is that stimulation of the median nerve first conveys inpulses to the brainstem and then to the sympathetic nervous system. Positive results from skin potentials therefore reflect transmission of sympathetic impulses and should be associated with the maintenance of psychogenic erection. Negative results from skin potentials should, on the other hand, reflect interruption of the connections between higher centres and sympathetic innervation and should be associated with a loss of psychogenic erectile potential.

In a current study, with Dr Pierre-Marie Gonnaud from the Jules Courmont Hospital (Lyon, France), we are exploring the role of these potentials in the sexual diagnosis of spinal cord injured men. The preliminary data are encouraging and suggest that skin potentials from the penis can discriminate between subjects who maintain thoracic-lumbar sympathetic activity necessary for psychogenic erections and those who lose the necessary connections to allow transmission of psychogenic erections. These preliminary findings suggest that skin potentials could perhaps be used as an objective assessment of the functional state of TL innervation.

\section{Sexological interview versus functional interview}

Aside from the clinical examination, or in the absence of it, the sexological interview remains a source of information on the sexual difficulties of spinal cord injured patients. However, since spinal cord injured men lack sensation below the lesion level they often underestimate their actual sexual capacity. ${ }^{41,50}$ Questions on the sexual interview are therefore complemented by questions on somatic and visceral function which are used to estimate the functional state of the sacral and/or TL pathway.

Table 2 illustrates these additional questions on visceral function and show how they can provide indications on the functional state of the sacral and thoracic-lumbar pathway. Some questions relate to episodes of automatic dysreflexia, which can provide an indication of spontaneous ejaculations, while others focus on rectal or bladder function to provide indications on sphincter activity. For example, the presence of continuous leaks of urine can be associated with poor urethral sphincter activity and can be a sign of poor sacral innervation. Conversely, ability to urinate while relaxing the sphincter is a sign of remaining connections 
Table 2 Clinical interview

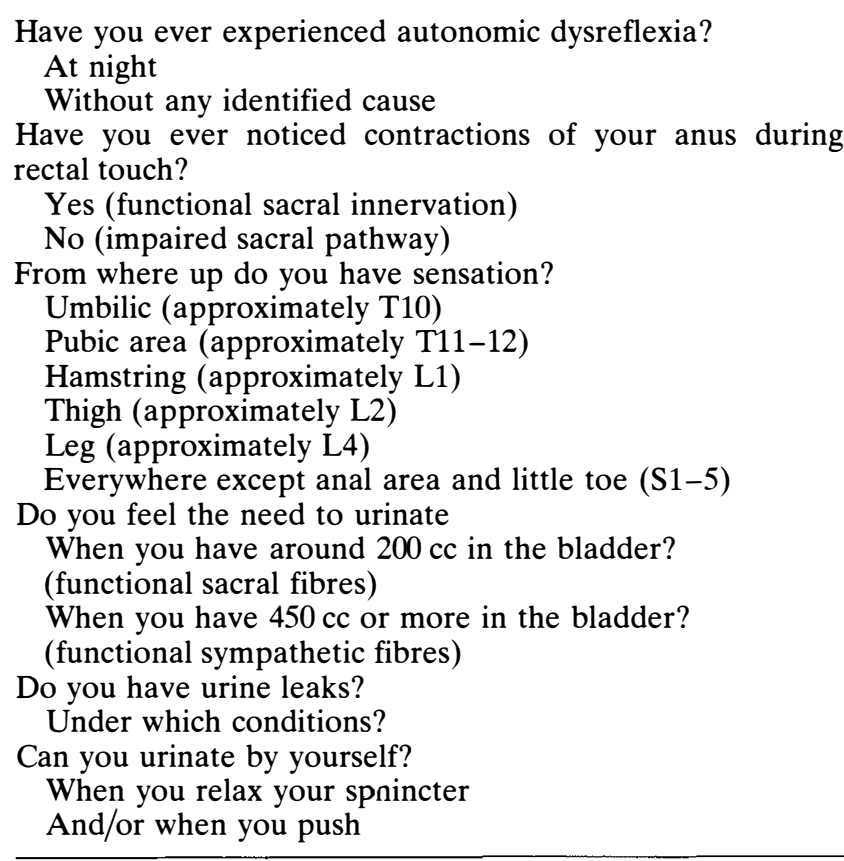

between higher centres and the sacral pathway. Presence of a perceptible need to urinate also provides information on remaining neural connections. Since spinal cord injured men are used to measuring the urine volume during rehabilitation, they can estimate the volume of urine voided during micturition. Four levels in the need to urinate have been described: ${ }^{51}$ level 1 reflects a first need quickly forgotten and perceived at approximately 200 cc of bladder volume; level 2 reflects a pressing need; and levels 3 and 4 reflect urges to urinate (urgent and imminent) that start at approximately $400 \mathrm{cc}$ of bladder volume. The first two levels are conveyed by sensory inputs originating from the sacral segments. Levels 3 and 4, in contrast, convey sensory inputs from distension of the bladder and are transmitted via the T10-L2 spinal segments. ${ }^{51}$ Needs to urinate can therefore be used as signs of functional sacral or thoracic-lumbar fibres.

As far as rectal function is concerned, presence or absence of reflex activity from the anal sphincter can be an indication of functional or impaired sacral activity and can be assessed verbally from the patient who must perform digital faecal evacuation.

These overall questions on visceral activity provide an initial classification based on the functional state of the sacral pathway. They are complemented by questions on skin sensation and anaesthesia to provide an estimate of dermal innervation. The combined information helps the clinician conclude on a final classification of the patient (AP, BTW, CT or CE) which will provide a prognosis of residual sexual potential. If the patient's report of sexual function does not conform to this prognosis, the clinician may further investigate a psychogenic contribution to the dysfunction.

\section{Therapeutic interventions}

Therapeutic interventions that are currently offered to spinal cord injured patients concentrate on the intracavernous injections of vasoactive drugs such as papaverine..$^{1-3,52,53}$ prostaglandin ${ }^{3}$ and other combinations, ${ }^{54-56}$ as well as the use fo vacuum devices ${ }^{4-6}$ and surgical implants of penile prothesis ${ }^{7,8}$ with the latter being used less often since the appearance of intracavernous treatments. ${ }^{56,57}$ While these strategies are unquestionably effective to palliate the sexual dysfunction of spinal cord injured men, we believe that the residual sexual capacity should not be ignored. On the one hand, this residual capacity may be of crucial importance to the subject to recover a sense of control over his intimate life, and on the other hand, this initial post-traumatic potential can possibly be maximised through a sexual rehabilitation programme on which we will give examples below.

\section{Intracavernous injections}

Among the palliative treatments for sexual dysfunctions in spinal cord injured men is the technique of intracavernous injections. This has been found to be very powerful in overcoming erectile dysfunctions ${ }^{1,2,52}$ and to be particularly indicated in this population of patients. ${ }^{52}$ Our data on papaverine injections confirm these results and show that the drug is equally effective for subjects of various lesion groups, whether AP, BTW, CT or CE. ${ }^{58}$ However, we have questionned the effectiveness of papaverine as a function of the individual's residual sexual capacity. Our preliminary results $^{58}$ show that the pharmacological effect alone of papaverine is significantly smaller than the effect of papaverine combined with the individual's residual sexual functional capacity. In addition, our results show that an apparently ineffective dose of papaverine, from a strict pharmacological point of view, can become effective when combined with the individual's residual capacity. ${ }^{58}$ These results show that if papaverine is definitely effective for spinal cord injured patients, lower doses could be explored if the individual was trained to use his residual sexual capacity, a finding which may be of particular interest when one considers the concerns shared by both patients and clinicians on the long term effects of pharmacological treatments.

\section{Sexual rehabilitation}

Sexual rehabilitation of spinal cord injured subjects should emphasise the individual's residual capacity as a function of remaining functional pathways and should maximise this early post-traumatic potential. According to this view, lesions located above the dual innervation of the genital system (AP) or between the two pathways (BTW) should be trained to use a reflexogenic mode of sexual function, while those with lesions to the conus terminalis (CT) or cauda equina (CE) should be trained to use a psychogenic mode of function. In the latter cases, a cognitive-behavioral treatment can be applied whereby the individual is 
asked to imagine different sources of arousing stimuli, including those used prior to the spinal trauma and those explored since the trauma. Stimuli that inhibit, or used to inhibit, arousal should also be explored to investigate whether the current mode of sexual function is somehow inhibitory. The identified arousing stimuli could be measured using a subjective intensity scale aimed at exploring possible control over the sexual response. Mental imagery would then be complemented with home exercises aimed at applying the imagined situations in real-life conditions. While these cognitive-behavioral strategies may be effective in exploring the various stimulation sources than can induce and control erection, they may also serve to control premature emission in patients with lower lesion levels (primarily CT lesions) and who experience almost immediate dribbling emission upon psychogenic arousal. ${ }^{41}$

Individuals with higher lesion levels (AP, BTW) should, in contrast, be offered a cognitive-behavioral programme aimed at using genital or perineal stimulation to elicit penile responses. Stimuli that elicit erection should be identified, as well as those inhibiting the response. For example, we have noticed in our clinical setting that pressure stimulation of the glans penis (applied during evaluation of the bulbocavernosus reflex) can trigger erection, while rubbing of the glans penis is often reported as inhibiting the response. Similarly, motion during penetration can stimulate erection, while bending the penis or pushing it backward may inhibit the response without the individual being aware of this otherwise painful sensation. Finally, some patients report using their spasticity to trigger an ejaculatory response in the last stage of arousal, but similarly caution not to use such spasticity in the early stage of arousal as it can inhibit subsequent responses of climax. The use of spasticity with ejaculation can be associated with autonomic dysreflexia.

Subjects with higher lesions should therefore be trained to explore these, and other, stimulation sources to induce or inhibit erectile responses. The procedure should be advised as home exercises during masturbation by the patient himself, and during fondling with the partner, so that both patient and partner become aware of the positive and negative body responses to stimulation before intercourse is achieved.

As we were exploring these various strategies for clinical purposes we developed a research project, with Dr Christine Fournier from the Rehabilitation Institute of Montreal (Canada), on a sexual rehabilitation programme for spinal cord injured men. The programme is based on reinforcement of perineal muscles which have been suggested to play a role in the pumping of blood into the penis. ${ }^{59}$ The programme is applied on higher lesion subjects, who maintain sacral activity and therefore perineal muscle contractions, as well as lower lesion subjects who exhibit partial lesions and who maintain partial innervation of perineal muscles. The subjects are trained to use their optimial mode of stimulation to achieve initial tumescence (ie reflexogenic or psychogenic based on their classification) and to increase this initial response by recruiting muscular activity during pressure stimulation of the glans penis to pump the blood into the penile cavities. The preliminary results are very encouraging although few subjects have been test.

The sexological evaluation of spinal cord injured patients therefore appears to be beneficial and should not be viewed as a sterile activity in clinical practice. The evaluation not only offers control to the paraplegic or tetraplegic individual over his sexual life, but also opens the field to therapeutic approaches combining various existing strategies and maximising the residual function, which is the primary goal of any rehabilitation programme.

\section{Acknowledgements}

The authors wish to thank Danielle Choquette, Pierre Gougeon, Johanne Gravel, Claudine Belley and Brigitte Roy for their technical assistance on the various research projects. The authors also thank Serge Raymond from the Quebec Paraplegic Association for his contribution on insights as to the sexual function of spinal cord injured men. These research projects were funded by FCAR and FRSQ (Quèbec, Canada) and by the Foundation Jacques Cartier (Paris, France) for France-Québec collaborations.

\section{References}

1 Bodner DR, Lindan R, Leffler E, Kursh ED, Resnick MI. The application of intracavernous injection of vasoactive medications for erection in men with spinal cord injury. J Urol 1987; 138: 310-311.

2 Bodner DR, Leffler B, Frosti F. The role of intracavernous injection of vasoactive medication for the restoration of erection in spinal injured males: a three year follow-up. Paraplegia 1992; 30: $118-120$.

3 Lee LM, Stevenson WD, Szasz G. Prostaglandin E1 versus phentolamine-papaverine for the treatment of erectile impotence: a double blind comparison. J Urol 1989; 141: 549-550.

4 Heller L et al. An open trial of vacuum penile tumescence: constriction therapy for neurological impotence. Paraplegia 1992; 30: 550-553.

5 Nadig PW, Ware FC, Blumoff R. Non-invasive device to produce and maintain an erection-like state. Urology 1986; 27 : $126-131$

6 Zasler ND, Ikatz PG. Synergist erection system in the management of impotence secondary to spinal cord injury. Arch Phys Med Rehabil 1989; 70: 712-716.

7 Golji H. Experience with penile prosthesis in spinal cord injured patients. J Urol 1979; 121: 288-289.

8 Iwatsubo E et al. Non-inflatable penile prothesis for the management of urinary incontinence and sexual disability of patients with spinal cord injury. Paraplegia 1986; 24: 307-310.

9 Kaplan H. The New Sex Therapy. New York: Brunner Mazel, 1974, pp 255-288.

10 LoPiccolo J, LoPiccolo L. Handbook of Sex Therapy. Plenum Press: New York, 1978, pp 1-18.

11 Masters WH, Johnson VE. Human Sexual Inadequacy. Little, Brown and Company, Boston, 1970, pp 450-551.

12 Paolino TS, McCrady BS. Marriage and Marital Therapy: Psychoanalytic, Behavioral and Systems Theory Perspectives. Bunner/Mazel, New York 1978.

13 Kenepp D, Gonick P. Home monitoring of penile tumescence for erectile dysfunction. Urology 1979; 14: 261-264.

14 Rosen RC, Keefe FJ. The measurement of human penile tumescence. Psychophysiology 1978; 15: 366-376.

15 Lavoisier $\mathrm{P}$ et al. Validation of a non-invasive device to 
measure intracavernous pressure as an index of penile regidity. Br J Urol 1990; 65: 624-628.

16 Frohrib D et al. Characterization of penile erectile states using external computer-based monitoring. Transactions. ASME 1987; 109: 110-114.

17 Knaeko S, Bradley WE. Evaluation of erectile dysfunction with continuous monitoring of penile rigidity. J Urol 1986; 136: $1026-1029$.

18 Bradley WE. New techniques in evaluation of impotence. Urology 1987; 29: 383-388.

19 Karacan I, Salis P, Williams RL. The role of the sleep laboratory in diagnosis and treatment of impotence. In Williams RL, Karacan I (eds). Sleep Disorders, Diagnosis and Treatment. Wiley: New York, 1978, pp 353-382.

20 Barry JM, Blank B, Boileau M. Nocturnal penile tumescence monitorings with stamps. Urology 1980; 15: 171-172.

21 Bertini J, Boileau MA. Evaluation of nocturnal penile tumescence with potentest. Urology 1986; 27: 492-494.

22 Marshall $\mathrm{P}$ et al. Nocturnal penile tumescence recording with stamps: a validity study. J Urol 1982; 128: 946-947.

23 Ek A, Bradley WE, Krane RJ. Nocturnal penile regidity measured by the snap-gauge band. J Urol 1983; 129: 964-966.

24 Virag R, Virag H, Lajujie J. A new device for measuring penile rigidity. Urology $1985 ; 25$ : $80-81$.

25 Althof SE, Levine SB. Clinical approach to the sexuality of patients with spinal cord injury. Urol Clin North Am 1993; 20: $527-534$.

26 Smith EM, Bodner DR. Sexual dysfunction after spinal cord injury. Urol Clin North Am 1993; 20: 535-542.

27 Giuliano $\mathrm{F}$ et al. Commandes nerveuse périphériques de l'érection. Andrologie 1993; 1: 123-127.

28 Dail WG, Trujillo D, Delarosa D, Walton G. Autonomic innervation of the reproductive organs: analysis of the neurons whose axons project in the main penile nerve in the pelvic plexus of the rat. Anat Rec 1989; 224: 94-101.

29 McKenna KE, Nadelhaft I. The organization of the pudendal nerve in the male and female rat. J Comp Neurol 1986; 248: 532-549.

30 Hart BL. Sexual reflexes and mating behavior in the male rat. J Comp Physiol Psychiatry 1968; 65: 453-460.

31 Hart BL. Sexual reflexes in the male rat after anesthetization of the glans penis. Behav Biol 1972; 7: 127-130.

32 Hart BL. Hormones, spinal reflexes and sexual behavior. In: Hutchison JB (ed). Biological Determinants of Sexual Behavior. John Wiley \& Sons: New York, 1978, pp 319-347.

33 Sachs BD, Garinello LD. Spinal pacemaker controlling sexual reflexes in male rats. Brain Res 1979; 171: 152-156.

34 Sachs BD, Garinello LD. Hypothetical spinal pacemaker regulating penile reflexes in rats: Evidence from transection of spinal cord and dorsal penile nerves. J Comp Physiol Psychiatry 1980; 94: 530-535.

35 Sachs BD, Meisel RL. The physiology of male sexual behavior. In: Knobil E \& Neill JD (eds). The Physiology of Reproduction. Raven Press: New York, 1988, pp 1393-1486.

36 Bors E, Comarr AE. Neurological disturbances of sexual function with special reference to 529 patients with spinal cord injury. Urol Survey 1960; 10: 191-222.

37 Chapelle PA, Durand J, Lacert P. Penile erection following complete spinal cord injury in man. Br J Urol 1980; 52: 216-219.

38 Comarr AE. Sexual function among patients with spinal cord injury. Urol Int 1970; 25: 134-168.
39 Dail WG, Walton G, Olmsted MP. Penile erection in the rat: Stimulation of the hypogastric nerve elicits increase in penile pressure after chronic interruption of the sacral parasympathetic inflow. J Auton Nerv System 1989; 28: 251-258.

40 Courtois FJ, MacDougall JC, Sachs BD. Erectile mechanism in paraplegia. Physiol Behav 1993; 53: 721-726.

41 Courtois FJ, Charvier KF, Leriche A, Raymond DP. Sexua function in spinal cord injury men. I. Assessing sexual capability. Paraplegia 1993; 31: 771-784.

42 Courtois F, Charvier K, Leriche A. Fonction sexuelle et bilan sexologique de l'homme paraplégique et tétraplégique. Andrologie 1994; 2: 142-153.

43 Fisher C, Gross J, Zuch A. Cycle of penile erection synchronous with dreaming (REM) sleep. Arch Gen Psychiatry 1965; 12: $29-45$.

44 Fisher $\mathrm{C}$ et al. Evaluation of nocturnal penile tumescence in the differential diagnosis of sexual impotence. Arch Gen Psychiatry 1979; 36: 431-437.

45 Fisher $\mathrm{C}$ et al. The assessment of nocturnal REM erection in the differential diagnosis of sexual impotence. J Sex Marital Ther 1975; 4: 277-289.

46 Karacan I. Clinical value of nocturnal erection in the prognosis and diagnosis of impotence. Med Aspects Hum Sex 1970; 4: 27-34.

47 Courtois F, Charvier K, Roy B, Leriche A. Faux diagnostics d'impuissance chez l'homme paraplégique. 9e Congrés National de la SOFMERR, 1993, Nantes, France.

48 Bourcier A, Perrigot M. Neurophysiologie de la miction. J Gynecol Obstet Biol Reprod 10: 749-759.

49 Courtois $\mathrm{F}$ et al. D. Approche clinique en sexothérapie auprès de blessés médullaires. 8e Congrès National de la SOFMERR, 1993, St-Etienne, France.

50 Kennedy S, Over R. Psychophysiological assessment of male sexual arousal following spinal cord injury. Arch Sex Behav 1990; 19: 15-27.

51 Amarenco G, Lacroix P. Explorations Urodynamiques et Troubles de la Miction. Agence 3C: Issy-les-Moulineaux, 1988, pp 41-42.

52 Lloyd LK, Richards JS. Intracavernous pharmacotherapy for management of erectile dysfunction in spinal cord injury. Paraplegia 1989; 27: 457-464.

53 Kapoor VK et al. Intracavernous papaverine for impotence in spinal cord injured patients. Paraplegia 1993; 31: 675-677.

54 Earle CM et al. The role of intracavernosal vasoactive agents to overcome impotence due to spinal cord injury. Paraplegia 1992; 30: $273-276$

55 Costa $\mathrm{P}$ et al. Efficiency and side effects of intracavernous injections of moxisylyte in impotent patients: a dose-finding versus placebo. J Urol 1993; 149: 301-305.

56 Brindley GS. Cavernosal alpha-blockade: a new technique for investigating and treating erectile impotence. Br J Urol 1983; 143: $332-337$.

57 Virag R. Intracavernous injection of papaverine for erectile failure. Lancet 1982; 2: 938

58 Courtois $\mathrm{F}$ et al. Optimisation de la papavérine auprès du blessé mèdullaire. 63e Congrès de 1'ACFAS, 1995, Chicoutimi, Canada.

59 Karacan I, Aslan C, Hirshkavits M. Erectile mechanism in man. Science 1983; 220: 1980-1982.

60 Ditunno JF, Young W, Donovan WH, Creasey G. The international standards booklet for neurological and functional classification of spinal cord injury. Paraplegia 1994; 32: 70-80. 